\title{
LAS ESTRATEGIAS PREVENTIVAS INDIVIDUALES EN LA LUCHA ANTIVENÉREA: SEXUALIDAD Y ENFERMEDADES VENÉREAS EN LA ESPAÑA DEL PRIMER TERCIO DEL SIGLO XX
}

\author{
por \\ RAMÓN CASTEJóN BOLEA \\ Universidad Miguel Hernández, Alicante
}

RESUMEN: Se estudian las respuestas médicas generadas a finales del siglo XIX y el primer tercio del siglo XX en relación con las estrategias preventivas individuales en la prevención de las enfermedades venéreas y los debates generados en torno a la abstención sexual y a la utilización de métodos de profilaxis física y química.

Palabras Clave: Enfermedades venéreas. Profilaxis física y química. Continencia sexual. España. Primer tercio del siglo XX.

\begin{abstract}
This article studies the medical responses at the end of the nineteenth and the first third of the twentieth century towards individualized preventive strategies against venereal disease contagion. The article goes on to look at debates which emerged on the subject of sexual abstention and the use of barrier and chemical methods of prophylaxis.
\end{abstract}

KEY WORDS: Venereal disease. Barrier and chemical prophylaxis. Sexual continence. Spain. First third of the twentieth century.

En el marco de la clásica etiología establecida entre enfermedades venéreas y prostitución, la verdadera obsesión por el contagio y desarrollo de la sífilis y otras enfermedades venéreas, uno de los grandes temores del siglo XIX, iba a mover tempranamente a médicos e higienistas españoles, desde los tiempos del trienio constitucional, a proponer la adopción del sistema reglamentarista y a no contentarse con su mera y por otra parte ineficaz represión, dentro desde 
luego de una amplia y constante polémica entre partidarios y adversarios de la reglamentación de la prostitución ${ }^{1}$.

A finales del siglo XX y en el primer tercio del siglo XX, frente a la ineficacia de tal reglamentación, ya generalizada en todo el país, se impulsaron pues estrategias preventivas individuales en la lucha contra las enfermedades venéreas, generándose un debate en torno a la abstención sexual y a la utilización de métodos de profilaxis física y química².

Alrededor de 1880, el debate médico sobre la conveniencia de enfrentarse al aumento de las enfermedades venéreas había sido resuelto con la firme convicción de que se debían tomar medidas preventivas para atajar los estragos causados por la sífilis y demás enfermedades venéreas. Este espíritu intervencionista y el rechazo del silencio público que rodeaba a las enfermedades venéreas se enmarca en una transformación que desde la visión de la enfermedad como «pecado individual» deja paso a la visión de la enfermedad como un ataque a la sociedad, como un peligro social ${ }^{3}$.

\section{UN PELIGRO SOCIAL}

La nueva visión, la construcción de la sífilis como un peligro social, ya era una realidad a principios del siglo XX, fundamentada en los daños que acarreaba al individuo, a la familia, a la sociedad y a la especie. En consecuencia, la sociedad tenía derecho a defenderse de ella. Por ejemplo, el sifiliógrafo francés Alfred Fournier había expuesto en la I ${ }^{a}$ Conferencia Internacional para la profilaxia de las enfermedades venéreas, celebrada en Bruselas en 1899, las razones para considerar la sífilis como un peligro social ${ }^{4}$.

Para España, José Luis Aranguren ha expuesto la idea de defensa social que aparece tras la Revolución de 1868:

«[...] Existe también toda una tradición de positivismo derechista, que trae su origen del mismo Comte [...]. Según tal versión derechista de la sociedad como un «organismo», este organismo social derechista necesita defenderse de sus enemigos, los que pretenden subvertir el «orden social». Así surgió la idea de la «de-

1 GuEREÑA, Jean-Louis: La prostitución en la España contemporánea, Madrid, Marcial Pons Historia (Estudios), 2003, pp. 58-75.

2 CASTEJÓN BOLEA, Ramón: «Enfermedades venéreas en la España del último tercio del siglo XIX. Una aproximación a los fundamentos morales de la higiene pública», Dynamis (Granada), Vol. 11 (1991), pp. 239-261, y Moral sexual y enfermedad: La medicina española frente al peligro venéreo (1868-1936), Granada, Universidad de Granada-Instituto Alicantino de Cultura «Juan GilAlbert», 2001, 296 p. (especialmente el cap. III, cuyos análisis recogemos en parte, «Estrategias preventivas individuales, propaganda antivenérea y educación sexual», pp. 137-207).

3 Temkin, O.: «On the History of 'Morality and Syphilis'«, en The Double Face of Janus and Other Essays in the History of Medicine, Baltimore, J. Hopkins University, 1977, pp. 472-484.

4 García Fraguas, José Esteban: Estudios y observaciones de amatoria sexualis. I. Amor libre $y$ prostitución, Barcelona, Biblioteca de la Regeneración Física, s.f. [1908], p. 321. 
fensa de la sociedad» [...] en España, tras la revolución de 1868, ante la amenaza [...] de la Internacional»s.

El concepto positivista de defensa social, como vemos, se desarrolla tanto frente al «desorden social» generado por los movimientos obreros subversivos como frente al «desorden moral» del que es expresión la sífilis. Las razones que produjeron esa nueva actitud en los médicos para sacar a la luz e intervenir en el peligro venéreo fueron, a nuestro entender, varias.

En primer lugar, cabe tener en cuenta las cifras que presumiblemente alcanzaron las enfermedades venéreas en las poblaciones urbanas:

«Hay una enfermedad que ha conservado el triste privilegio de diezmar las poblacionès, eligiendo principalmente sus víctimas en la juventud. [...] La sífilis es la gran plaga de la generación actual. En la atención de los médicos, en la de los hombres encargados de la administración, debe ocupar un lugar preferente. [...] Es un error considerarla como un mal poco alarmante porque sus destrozos no sean rápidos, y no aparezcan rodeados del fúnebre fragor de una epidemia»6.

La migración urbana, aunque sea un fenómeno tardío en nuestro país en comparación con el resto de Europa, ya producía a finales del siglo XIX una corriente poblacional fundamentalmente dirigida hacia Madrid, Barcelona y Vizcaya ${ }^{7}$. Madrid aumenta así su población en el periodo de 1850 a 1900 de 281.000 a 539.000 habitantes y Barcelona pasa de 178.000 a 533.000 habitantes $^{8}$.

La movilidad poblacional y las aglomeraciones urbanas conllevaban tanto un aumento de la prostitución como del intercambio sexual y, en consecuencia, un previsible aumento de las enfermedades venéreas. Pero no era solamente la percepción del aumento de estas enfermedades lo que alarmaba a los observadores médicos e higienistas, sino también lo que reflejaban. La extensión de las enfermedades venéreas se convirtió en efecto en un indicador de la ruptura de la norma sexual, de los ataques que sufría la familia y al matrimonio:

«Y no es sólo la Medicina la que está demandando la pronta desaparición de las enfermedades sifilíticas: lo exige también la moral, guardadora de la paz de las familias»9.

5 ARAnguren, José Luis L.: Moral y Sociedad. La moral española en el siglo XIX, Madrid, Taurus, 1982 [ $1^{\text {a }}$ ed., 1965], pp. 142-145.

6 GARCía DuARTE, E.: Es un deber de los Gobiernos procurar la extinción de la sífilis. Higiene pública de la siffilis. Discurso inaugural leído en la solemne apertura de la Real Academia de Medicina y Cirugía de Granada el 12 de enero de 1862, Granada, Real Academia de Medicina y Cirugía de Granada, 1862, pp. 9 y 14.

7 NADAL, Jordi: La población española (Siglos XVI a XX), Barcelona, Ed. Ariel, S.A., 1984, p. 229.

8 TUÑón DE LARA, Manuel: «De la Restauración al desastre colonial», en TUÑón DE LARA, M., BAhamonde, Á. y ARóstegui, J.: La España de los caciques. Del sexenio democrático a la crisis de 1917, Madrid, Historia de España 16, Año VII ${ }^{\circ}$, extra XXII, 1982.

9 PRATS Y BOSCH, Dr. Antonio: La prostitución y la sifilis: Ensayo acerca de las causas de la propagación de las enfermedades sifilíticas y los medios de oponerse a ella, Barcelona, Librería de El Plus Ultra, 1861, p. 9. 
Similares palabras se encontraban en un artículo publicado en 1915-1916 en La Clínica Moderna:

«Pero no es sólo la Medicina, o mejor dicho la Higiene, la que demanda la desaparición de las enfermedades venéreas, sino que lo exige también la moral, guardadora de la paz de las familias» 10 .

Para la moral burguesa, en la que la familia y el mundo doméstico ocupaban un lugar fundamental, las enfermedades venéreas se convertían pues en un ataque a la institución misma.

Como consecuencia del desarrollo de la venereología, otros elementos científicos se sumaron también a la situación de «alarma social» y consolidaron la construcción de la sífilis y de la blenorragia como un peligro social. En 1859, Rudolf Virchow había establecido que la infección podía ser transferida a través de la sangre a los órganos internos, y para 1876 la sífilis cardiovascular había sido documentada claramente en la literatura médica ${ }^{11}$. Fournier afirmó el origen sifilítico de la tabes dorsal en 1875, y poco después el de la parálisis general progresiva; para 1894, ya había establecido el concepto de parasífilis ${ }^{12}$. Estudios posteriores a la identificación del gonococo por Neisser en 1879 demostraron que la gonorrea podía producir una serie de consecuencias orgánicas que cambiaron su perfil de enfermedad trivial para adjudicarle una mayor gravedad. Anteriormente, Emile Noeggerath, un médico alemán, había establecido la relación entre la infección blenorrágica y la esterilidad femenina como consecuencia de la infección de las trompas de Falopio ${ }^{13}$.

Estos hallazgos científicos, además de aportar credibilidad científica a los venereólogos en su lucha contra el charlatanismo, dotaban a los médicos de nuevas razones para justificar la necesidad de sacar a la luz e intervenir en el problema venéreo, tanto por la gravedad de los nuevos cuadros patológicos descritos a nivel individual como por las consecuencias para la descendencia y la especie, a la luz de las teorías degeneracionistas imperantes y de las incipientes preocupaciones eugénicas.

Además, si la enfermedad era considerada anteriormente como un «pecado individual» —en justo castigo por la transgresión-, la aparición de las «víctimas inocentes» que habían adquirido la enfermedad por vías de contagio distintas de la relación sexual ilícita, dividía a los enfermos en «culpables» e «inocen-

10 ReY-Stolle y RaviÑa, C.: «La blenorragia y el matrimonio», La Clínica Moderna, vol. 14 (1915), $\mathrm{n}^{\circ} 261$, pp. $756-760$, vol. 15 (1916), $\mathrm{n}^{\circ} 262$, pp. $17-28, \mathrm{n}^{\circ} 263$, pp. $49-59$, y $\mathrm{n}^{\circ} 264$, pp. 84-89.

11 CASSEL, J.: The Secret Plague. Veneral Disease in Canada 1838-1939, Toronto, University of Toronto Press, 1987, p. 28. Ver BrandT, A. M.: No Magic Bullet. A Social History of Venereal Disease in the United Status since 1880, Oxford, Oxford University Press, 1988, 245 p.

12 CASSel, J.: The Secret Plague, op. cit., p. 29; QUeTel, Claude: History of Syphilis, Cambridge, Polity Press, 1990, p. 134.

13 CASSEL, J.: The Secret Plague, op. cit., p. 27. 
tes». Había, pues, que tomar medidas para atajar un mal que ya no seleccionaba a sus víctimas únicamente entre las "culpables». Amancio Peratoner, autor fecundo como divulgador y popularizador de temas sexuales a finales del siglo XIX, lo exponía así:

«[...] El mal de que se trata elige también sus víctimas no sólo entre los que a él se exponen voluntariamente, sino entre los que ni quieren, ni pueden exponerse: un infante lo aporta al nacer, una mujer virtuosa lo recibe de su marido, una nodriza de su cría y lo transmite a sus propios hijos, etc. ¿Qué pensar, pues, de una justicia que confundiese en un mismo castigo a inocentes y a culpables?»14.

Ciertas ideas y creencias populares impedían además mantener la "conspiración de silencio» sobre las enfermedades venéreas. En sus Elementos de higiene naval, Ángel Fernández Caro lo reflejaba en 1879:

«Existe en el pueblo y en algunas personas de posición más elevada una especie de vanagloria en haber padecido afecciones venéreas; imagínanse sin duda que son más varoniles si pueden ostentar las cicatrices de unos cuantos bubones. La instrucción y la educación moral concluirán con estos restos de salvajismo»15.

Por otra parte, la nueva situación creada con las preocupaciones y las ansiedades que generaban las enfermedades de transmisión sexual a finales del siglo XIX - las imágenes del miedo a la sífilis y a sus consecuencias quedaron así reflejadas en la obra de diversos pintores de finales del XIX y de principios del XX, como Mors Syphilitica de Félicien Rops, Herencia de E. Munch y el cartel de Ramón Casas, Sífilis ${ }^{16}$ - conllevó la inclusión de este grupo de enfermedades dentro de las denominadas «enfermedades sociales»:

«El siglo XIX conoce, igualmente, la concreción del término «enfermedad social» para designar situaciones «inherentes a la organización viciosa de la sociedad» (Hauser). Desde una perspectiva sociológica, los postulados organicistas imperantes introdujeron la analogía médica para identificar como «patología social» las alteraciones del orden económico, político y moral vigente»17.

14 Peratoner, Amancio: El mal de Venus; estudio médico-popular sobre las enfermedades venéreas y sifilíticas tomadas de las obras de los eminentes sifiliografos Belhomme, Cullevier, Diday, Lancereaux, Martín, Mireur, Ricord, etc. y completado con la versión (refundida) del interesante opúsculo del doctor Langlebert sobre el arte de preservarse del contagio y de los charlatanes que con sus consecuencias especulan, Madrid, Simón y Osler, 1881, p. 204.

is Fernández Caro y Nouvilas, Ángel: Elementos de bigiene naval, Madrid, Imp. de Aribau y $C^{a}, 1879$, p. 448.

16 BORnAY, E.: Las hijas de Lilith, Madrid, Ediciones Cátedra, 1990; p. 256.

17 RODRÍGUEZ OCAÑA, Esteban: La constitución de la Medicina Social como disciplina en España (1882-1923), Madrid, Ministerio de Sanidad y Consumo (Colección Textos Clásicos Españoles de Salud Pública, vol. 30), 1987, p. 23. 
Se entremezclan así en las enfermedades venéreas tanto el concepto de enfermedad social cuyo origen estaría en la alteración del orden moral, como el de peligro social por sus consecuencias y repercusiones que trascendían la esfera individual. De esta manera, la Higiene Pública, y posteriormente la Medicina Social, entendieron que la lucha contra este grupo de enfermedades caía de lleno en su ámbito de actuación ${ }^{18}$.

Este proceso de discusión pública de las enfermedades venéreas y de su principal foco en el discurso epidemiológico de la época, la prostitución, «en aulas y academias, en ateneos y reuniones científicas, en libros y periódicos científicos» ${ }^{19}$, tuvo como consecuencia un debate social sobre la higiene sexual personal y, en última instancia, trasladó elementos de la sexualidad desde el ámbito privado del hogar y la familia al terreno público de lo social ${ }^{20}$.

\section{EDUCAR A LAS POBLACIONES}

Todas las razones expuestas anteriormente llevaron a los médicos a proponerse varios objetivos para afrontar e intervenir en el problema de las enfermedades venéreas. Si en otros trabajos hemos apuntado los instrumentos jurídicos, organizativos y asistenciales utilizados para enfrentarse a este grupo de enfermedades $^{21}$, pretendemos ahora explorar cuáles fueron las teorizaciones y prácticas en el terreno de la educación antivenérea y de la prevención individual.

El núcleo de la educación antivenérea se centró, en primer lugar, en «ilustrar» al pueblo acerca de los grandes peligros que suponían estas enfermedades, así como de sus graves consecuencias para la familia, la sociedad y la raza; en segundo lugar, en divulgar una serie de conocimientos sobre las enfermedades venéreas y las prácticas preventivas individuales para evitar la transmisión:

«Divulgar por el pueblo ideas exactas sobre la enfermedad sifilítica y el tratamiento que exige, recomendando sobre todo la curación pronta de los síntomas

\footnotetext{
18 GelaberT, Enrique: «De la prostitución, en sus relaciones con la Higiene, en el doble concepto de la profilaxis de la sífilis y de la reglamentación", en Acta de la sesión pública inaugural celebrada en 14 de enero de 1886 por la Academia y Laboratorio de Ciencias Médicas de Cataluña. Discurso leído en la sesión inaugural por el Dr. D. --, Barcelona, Establecimiento Tipográfico de los Sucesores de N. Ramírez y Ca, 1886, p. 28.

19 MARSILLACH Y PARERA, Juan: ¿Qué medios deberá aconsejar el médico-bigienista al gobierno para atenuar los funestos efectos ocasionados por la prostitución? Memoria que en ejercicio para el grado de doctor en Medicina y Cirugía leyó el día $1^{\circ}$ de Julio de 1869 D. --, Barcelona, Establecimiento Tipográfico de Jaime Jesús Roviralta, 1869, p. 3.

20 WEEKS, Jeffrey: Sex, Politics $\mathcal{E}$ Society. The regulation of sexuality since $1880,2^{\mathrm{a}}$ ed., LondonNew Cork, Longman, 1989 [1 $1^{\text {a }}$ ed., 1981], p. 145; BRANDT, A. M.: No Magic Bullet, op. cit., p. 6.

21 CASTEjón BOLEA, Ramón: Moral sexual y enfermedad, op. cit., pp. 27-135.
}

Hispania, LXIV/3, núm. 218 (2004) 923-946 
locales o peligrosos [...]. Ilustrar al público en orden a la confianza que merecen los preservativos y los titulados específicos» ${ }^{22}$.

Y, finalmente, se trataba de prevenir sobre los perniciosos efectos de abandonarse en manos de charlatanes y curanderos:

«Prohibir enérgicamente la venta de remedios secretos y los anuncios de curaciones maravillosas, y perseguir con ahinco el curanderismo y el charlatanismo médico» ${ }^{23}$.

A finales del siglo XIX, este último tema ofrecía sin embargo dificultades insoslayables. De un lado, el monopolio médico no estaba aún definitivamente consolidado ${ }^{24}$, y de otro no se disponía de recursos terapeúticos efectivos. Además, los tratamientos disponibles no estaban exentos de graves efectos secundarios y de un marcado carácter punitivo.

A estos objetivos se sumaba la pretensión de crear un movimiento de regeneración moral como respuesta a las ansiedades y miedos producidos por los cambios sociales y los procesos de aglomeración urbana ${ }^{25}$, movimiento en el que, como veremos, la abstención sexual ocuparía un lugar estratégico.

La segunda Conferencia Internacional para la prevención de la Sífilis y Enfermedades Venéreas, celebrada en Bruselas en 1902, había aprobado en dos de sus acuerdos la necesidad de difundir la importancia y la gravedad de estas enfermedades. También señaló como aspecto más importante de la prevención individual la necesidad de «enseñar a la juventud masculina» la importancia de la castidad y de la continencia.

Algunos médicos higienistas ya se manifestaban a finales del siglo XIX a favor de la continencia entre la juventud masculina:

«Debemos siempre los médicos [...] aconsejar a todos y especialmente a la juventud, que se abstenga de los placeres venéreos; haciéndola comprender que tras ellos van las enfermedades mencionadas revistiendo formas diversas, graves y mortales muchas veces» 26 .

\footnotetext{
22 MARSILLACH Y PARERA, Juan: ¿Qué medios deberá aconsejar el médico-higienista al gobierno para atenuar los funestos efectos ocasionados por la prostitución?, op. cit., p. 27.

23 Ibid.

24 Sobre la realidad de estas prácticas, ver, por ejemplo, AlBARRACín TEUlón, Agustín: «Intrusos, charlatanes, secretistas y curanderos", Asclepio (Madrid), vol. XXIV (1972), pp. 323-366.

25 VIÑETA-BELLASERRA, J.: La sífilis como becho social punible y como una de las causas de degeneración de la raza bumana. Discurso pronunciado en la Sociedad Econónomica Graciense de Amigos del País en la sesión del 8 de Marzo de 1885, Barcelona, Establecimiento tipográfico editorial La Academia, 1886, pp. 57-58.

${ }_{26}$ CORTÉs, L.: «Consideraciones generales acerca de la profilaxis de las enfermedades venéreas y sifilíticas», Gaceta Médica Catalana (Barcelona), nº 9 (1886), p. 330.
} 
Y, lo que era más importante, la Conferencia antes mencionada subrayaba que, desde el punto de vista médico, la castidad y la continencia no sólo no eran perjudiciales sino muy recomendables. Sin embargo, el aspecto más novedoso consistió en la recomendación de llevar a los educadores de la juventud «el problema de la educación racional y progresiva de las cuestiones de orden intersexual, bajo el punto de vista higiénico y moral ${ }^{27}$.

La consideración médica de la castidad y continencia como «virtudes muy recomendables» exigió un cambio en la idea médica que se tenía de la abstención sexual. La idea de la irrefrenabilidad de la sexualidad masculina y de las perjudiciales consecuencias que para el hombre tenía la castidad formaban parte en efecto de las ideas comunes sobre la sexualidad masculina:

«Hay sed que no se apaga si no se satisface, apetito que no se amengua si no se devora el lujurioso manjar»28;

«Sería preciso desconocer la índole del hombre y no tener en cuenta la fuerza casi irresistible con que el instinto reproductor le arrastra a los carnales deleites» 29 .

Entre nuestros médicos, destaca la labor divulgativa de Juan de Azúa, que en 1894 ya había expuesto sus ideas acerca de los Avisos sanitarios. Estos Avisos eran material impreso que recogía información sobre la enfermedad, sus modos de contagio y las precauciones que había que tomar y que eran repartidos, desde 1898, en las consultas del Hospital de San Juan de Dios, el hospital madrileño especializado en enfermedades venéreas.

Los Avisos sanitarios, presentados en el IX ${ }^{\circ}$ Congreso Internacional de Higiene y Demografía celebrado en Madrid en 1898, tuvieron muy buena acogida tanto en este congreso como en la segunda Conferencia Internacional de 1902 celebrada en Bruselas, donde fueron incluidos en los acuerdos. Además de este tipo de avisos, en los que se utilizaba como espacio para la propaganda el hospital y las consultas, Juan de Azúa proponía, en su proyecto de Reglamentación sanitaria de la prostitución de 1905, otros espacios para la propaganda. Así, describía otros tipos de Avisos sanitarios dirigidos a los clientes de las prostitutas y a los varones en general, «hombres de quince años en adelante», que presumiblemente utilizarían los servicios de las prostitutas:

27 PARDo Regidor, A.: Segunda Conferencia de Bruselas (10 al 6.de Septiembre de 1902) para la profilaxis de la sífilis y enfermedades venéreas bajo el patronato del Gobierno belga. Memoria presentada al Excmo. Ayuntamiento de Madrid por el Delegado del mismo en la citada Conferencia, Madrid, Imprenta Municipal, 1904, p. 36.

28 Gimeno, Amalio: Prólogo a LANGlebert, E.: Cartas a Emilio, sobre el arte de preservarse del venéreo y de los charlatanes que lo explotan, versión española de Álvaro ARNAU, Valencia, Imp. de M. Alutre, 1881, p. VII.

29 PiZARRo y GimÉnez, Manuel: Bases para la organización del servicio sanitario municipal de Sevilla. Memoria escrita y presentada al Exmo. Ayuntamiento Hispalense, Sevilla, Est. Tip. de LA ANDALucía, 1861, p. 57.

Hispania, LXIV/3, núm. 218 (2004) 923-946 
«Este factor masculino, tan activo como irresponsable, necesita ser combatido indirectamente, facilitando con todo género de recursos el tratamiento de los enfermos por la Venus e instruyendo a las gentes, en las ocasiones oportunas, acerca de la profilaxis de estas dolencias y de los daños que acarrea el adquirirlas»30.

Es importante reseñar que tanto el contenido como el espacio para la propaganda se ajustaban al reglamentarismo y a su modelo epidemiológico, que centraban las enfermedades venéreas en la prostitución. En efecto, se asumía que el varón inevitablemente frecuentaría a las prostitutas y, por tanto, la propaganda iba así dirigida a explicitar las técnicas preventivas pre y post-coitum y a informar a los clientes sobre las revisiones reglamentaristas y la manera de conocer el resultado de las revisiones. De esta forma, el burdel o la casa de la prostituta libre y las colectividades de varones eran ahora nuevos espacios de propaganda.

Los Avisos estaban redactados en estos términos:

«(Aviso núm. 1.- Papel blanco, fuerte. Letra clara y grande. Para las casas de tolerancia y las prostitutas inscritas)

Para librarse de que le peguen purgaciones, sífilis, chancros o llagas venéreas o sarna, hay que hacer antes de entrar con la mujer, que ésta enseñe a usted su cartilla y su retrato pegado a la misma. Si el retrato es de otra mujer o no quiere enseñar la cartilla, es que la mujer está mala. Cuando en la cartilla hay una estrella encarnada encima de la última firma del Médico, es que la mujer puede pegar algo.

Por precaución conviene se lave usted bien, por fuera, con agua, y si sabe manejarlo y lo lleva, con sublimado; que orine, y en cuanto llegue a su casa se ponga una inyección de una jeringuilla en el caño de la orina de la receta siguiente: (la fórmula que se adopte).

Téngase dos minutos dentro del caño de la orina».

Este aviso debía ser entregado a los clientes por las amas y las prostitutas; cuando el cliente era analfabeto, las prostitutas debían leerle el último informe que apareciera en la cartilla.

Igualmente, Azúa preconizaba la difusión entre los adolescentes de las nociones de "profilaxis de las enfermedades venéreas» y de la conveniencia de conocer los resultados del reconocimiento plasmados en la cartilla sanitaria. Las colectividades de varones - talleres, clases de higiene del bachillerato, servicio militar y academias militares, escuelas de artes y oficios, universidades, sociedades obreras, círculos y casinos, barcos de marina e incluso las minas- eran pues los espacios idóneos para difundir avisos como el siguiente:

30 AzÚA, Juan de: Reglamentación sanitaria de la prostitución, profilaxis y terapeútica colectivas de las enfermedades venéreas. Extracto de un informe oral, becho ante el Real Consejo de Sanidad, en la discusión de un proyecto de Reglamento de la sección de Higiene de la Prostitución. Junio, 1904, Madrid, Imprenta de Ricardo Rojas, 1905, p. 5. 
«Este Aviso se entregaría a los hombres de quince años en adelante y podría redactarse así:

A los muchachos les perjudica a la salud ir a mujeres antes de ser hombres fuertes y bien desarrollados.

Las mujeres que se van con cualquiera por dinero, suelen estar malas y pegan enfermedades graves y dolorosas.

Todas esas mujeres tienen obligación de enseñar al que va con ellas, un librito que se llama cartilla y tiene su retrato. Si hay una estrella roja en la última hoja escrita del libro, es que aquella mujer está mala.

También está mala si no quiere enseñar su cartilla con su retrato. Cuando ocurra algo de estas cosas, lo mejor es marcharse. Si no se hace así, puede cogerse alguna enfermedad»31.

A cargo de los médicos quedaba la realización de conferencias y para los padres «el consejo directo y discreto del que, por punto general, ha corrido ya esos peligros». La idea de que los médicos debían iniciar una campaña de divulgación popular - mediante conferencias y la elaboración de folletos sobre estas enfermedades, sus modos de contagio y sus graves consecuencias- prendió con facilidad en los médicos higienistas.

José Call, Inspector provincial de Sanidad de Madrid en 1908, incluía así entre las funciones de los médicos del sistema reglamentarista la realización de conferencias en centros populares o la elaboración de folletos sobre temas como: Origen del contagio blenorrágico, Consecuencia de la blenorragia para el desarrollo de las enfermedades del ovario en la mujer casada, Peligros del contagio sifilítico dentro del matrimonio, La sífilis y los manicomios, Blenorragia contagiada por conducto de mujer sana, El desgaste intelectual del crapuloso, Los abusos sexuales, el corazón y el pulmón, Los abusos sexuales y el estómago, etc. ${ }^{32}$.

Si la necesidad de extender a las poblaciones la idea de la importancia y gravedad de estas enfermedades no generó puntos de vista diferentes entre los médicos — pues todos compartían la creencia de que éste debía ser el primero y más importante apartado de la educación -, no ocurrió lo mismo con las estrategias preventivas individuales, entre las que se encontraban la abstención sexual, los métodos químicos y los físicos.

\section{LA PREVENCIÓN INDIVIDUAL: ABSTENCIÓN SEXUAL}

Si la difusión entre la población de la gravedad e importancia del "peligro venéreo» tomó cuerpo con rapidez entre los sectores médicos, la difusión de las estrategias preventivas individuales fue un problema de más difícil solución.

\footnotetext{
31 Ibid., pp. 6-9.

32 CALL, J.: Reglamentación higiénica de la prostitución. Estudio sanitario expuesto a la consideración de la Comisión Permanente de la Junta Provincial de Sanidad de Madrid por su secretario, el Inspector provincial de Sanidad, Dr. --, Madrid, Vicente Rico, 1908, p. 61.
} 
Por un lado, a la hora de abordar estas estrategias se enfrentaron dos posiciones, y de otro, es probable que la difusión de los métodos preventivos físicos y químicos se realizara principalmente al margen del monopolio médico.

Al hablar de dos posiciones, sintetizaremos éstas en lo que podríamos denominar la posición moral y otra posición más secularizada. Para la primera, fuertemente anclada en la moral católica, la lucha contra las enfermedades venéreas se cimentaba en la regeneración moral y en la castidad. La segunda posición, más cercana a planteamientos seculares, estaba más dispuesta a aceptar la realidad de la sexualidad fuera de los estrechos márgenes de la moral católica.

José Blanc y Benet, miembro de la Real Academia de Medicina de Barcelona, defendía así en 1905 la castidad que había propugnado la segunda Conferencia Internacional para la prevención de la sífilis y enfermedades venéreas en estos términos:

«Mas aquí no se trata de hacer que desaparezca inclinación alguna natural, no se trata de mutilar la naturaleza; únicamente nos proponemos ayudar a gobernarle, moderando sus exageraciones, hacer que sirva al fin que le corresponde.

[...] La continencia no mutila, puesto que no suprime la vida sexual; la encauza, la conduce a razón y lugar oportuno.

No hay razón para condenar la castidad»33.

Blanc y Benet consideraba que la continencia «constituye un deber riguroso para los que no son llamados a formar una familia» y, tras recordar que «el estado eclesiástico distínguese entre todos por su longevidad», planteaba lo que constituía el objetivo más importante de sus razonamientos: hacer triunfar la «doctrina de la continencia» en el «terreno de la fisiología», es decir dotarla de apoyo científico. Siguiendo a otro médico, León Corral y Maestro, que cita Blanc y Benet, era necesario pues rebatir esa idea común según la cual la continencia era una práctica insana:

«Citan algunos la continencia entre las causas que pueden producir a más de otros trastornos patológicos, cierto estado atrófico de los órganos reproductores, que habría de traer en pos de sí hasta la esterilidad; mientras que por otra parte vienen muchos defendiendo la irresistibilidad de los apetitos sexuales. $Y$ de aquí toman base ciertos escritores para hacer contra las buenas costumbres una campaña que es en el fondo tan anticientífica como inmoral» 34 .

Otra idea a desterrar era aquella que consideraba los apetitos sexuales como irrefrenables - se entienden los de los hombres-, idea que Blanc y Benet rechazaba citando a autores como Kraft-Ebing:

33 BLANC y BENET, José: La moderación de la libídine, Barcelona, Imp. de la Casa provincial de Caridad, 1905, pp. 7-8.

34 CORRAL y MAESTRO, León: Elementos de patología general, $2^{\text {a }}$ ed., Valladolid, 1900, cit. por BLANC Y BENET, José: La moderación de la libídine, op. cit., p. 17.

Hispania, LXIV/3, núm. 218 (2004) 923-946 
«Un gran número de hombres pueden poner freno a sus pasiones sin que, por esta continencia, se resienta su salud en lo más mínimo».

Richard von Kraft-Ebing publicó en 1886 la que probablemente fuera la primera obra específica, que de forma sistemática, abordó la conducta sexual: Psicopatía Sexual. Un estudio clínico forense ${ }^{35}$. Por otra parte, entre 1906 y 1913 se tradujeron en España las obras de Havelock Ellis, otro de los primeros sexólo$\operatorname{gos}^{36}$.

Pero no sólo, según Blanc y Benet, la continencia era sana, sino que su inobservancia era fuente de estragos:

«Estragos en la salud, en los intereses, en la mente, que apaga; en el carácter, que rebaja; estragos en la prole que degenera; en la paz del hogar que mata; en el destino de las naciones que conduce a la ruina» 37 .

Estos sectores médicos, entre los se encontraba Blanc y Benet, unían el aumento de las enfermedades venéreas a la situación de desorden social y moral:

«En lo que dice el Dr. Blanc acerca de la sífilis [...] se ven las tendencias de nuestra sociedad que, si no va con paso acelerado, tampoco anda con lentitud a la corrupción y a la degeneración de nuestra raza»38.

No veían por lo tanto otra solución que la regeneración mediante la moral católica. De esta manera, dificultaban un acercamiento más secularizado al problema de las enfermedades venéreas, y consecuentemente al desarrollo de un programa de propaganda antivenérea más basado en la ciencia:

"Los sistemas de moral que niegan al hombre todo principio trascendente y la efectividad de todo fin, han de ser causa del peligro social, siendo impotente el Estado para dominarlo; y sólo los sistemas de moral cristiana producen el orden y el bien de la sociedad, es decir, una civilización completa» 39 .

\footnotetext{
35 Moreno Jiménez, B.: La sexualidad bumana: Estudio y perspectiva histórica, Madrid, Fundación Universidad-Empresa, 1990, pp. 97-98.

36 VÁZQuez García, Francisco y MORENo MENGíbar, Andrés: Sexo y razón. Una genealogía de la moral sexual en España (Siglos XVI-XX), Madrid, Akal, 1997, p. 132.

37 BLANC Y BENET, José: La moderación de la libídine, op. cit., p. 101.

38 ANQuera y CAYla, Dr. Jorge: Discurso de respuesta en BlanC y Benet, José: Balance bigiénico de los modernos sistemas de moral. Discurso leído en la Real Academia de Medicina y Cirugía de Barcelona en el acto de la recepción del académico electo Dr. --, Barcelona, Imp. de Francisco J. Altés y Alabat, 1909, pp. 63-64.$$
39 \text { Ibid., p. } 64 .
$$

Hispania, LXIV/3, núm. 218 (2004) 923-946
} 


\section{LA PROFILAXIS FÍSICA Y QUÍMICA}

Frente a esta postura moral, para la cual sólo la abstención sexual era un método adecuado de prevención individual, se alzaba la otra posición más secularizada que defendía la utilización de otros métodos como la profilaxis química y física. Ello no quería decir que la mayoría de los médicos no propusieran igualmente la contención sexual como el método más efectivo, pero no la consideraban asumible por los varones o recomendaban la profilaxis si no conseguían apartarse del «vicio»:

«Bien está predicar la continencia y seguramente es éste el medio más eficaz para evitar las enfermedades venéreas, por lo menos por la vía sexual; pero no está bien cerrar los ojos a la realidad y afectar desconocer que, prácticamente, y en particular por lo que respecta al sexo masculino, la continencia no existe» 40 ;

«Por lo que respecta particularmente al sexo masculino, en las razas meridionales la continencia absoluta no existe» ${ }^{41}$.

Otros continuaron pensando que la continencia era contraria a la salud:

«La castidad ni existe, ni es recomendable; aconsejarla para no enfermar de los órganos genitales es como si recomendáramos no andar para no enfermar de los pies, o no leer para conservar la vista. Resulta tan idiota el consejo que no creemos merezca comentario» 42 .

En 1931, Antonio Navarro Fernández, dermato-venereólogo del Real Hospital del Buen Suceso de Madrid, reconocía que «hasta hace poco los médicos señalaban los peligros de la castidad; hoy en día no se cree tanto en ellos» ${ }^{43}$. Así pues, desde finales del siglo XIX, los médicos más intervencionistas y que propugnaban un papel activo de la Ciencia en la solución de los problemas sociales y morales asumieron la necesidad de la divulgación de los diferentes métodos químicos y físicos de prevención individual aplicables a las enfermedades venéreas.

La edición de obras traducidas de venereólogos franceses dedicadas a la instrucción de la juventud tenía ya antecedentes en nuestro país desde el último tercio del siglo XIX. Por ejemplo, la traducción de la obra ya citada de Langlebert Cartas a Emilio, sobre el arte de preservarse del venéreo y de los charlatanes que lo

40 Fernández de la Portilla, J. y Bravo Sanfeliú, J.: «Cómo debe organizarse en España la lucha antivenérea. Ponencia presentada en el II Congreso Nacional de Ciencias Médicas (Sevilla, Octubre, 1924)», Actas Dermo-Sifiliográficas, vol. 16 (1924), nº 5, pp. 312-334.

41 BRAvo, J.: «Profilaxis de la sífilis», en BARRIO De MEDINA, J. (Ed.): Tratado español de Venereología y Sifiliografía, Madrid, Javier Morata Editor, 1930, p. 860.

42 GARCía AyUSO: El enfermo venéreo. Manual popular de divulgación profiláctica, Madrid, Edit. «Plus Ultra», 1935, pp. 88-89. Ver MARCUSE: «Las consecuencias patológicas de la abstinencia sexual por Morhardt», Ecos Españoles de Dermatología y Sifiliografía, vol. 2 (1926), $\mathrm{n}^{\circ} 12$.

43 Navarro Fernández, Dr. Antonio: Presérvate del amor impuro (enfermedades venéreas), Madrid, Agencia Española de Librería, 1931, p. 14. 
explotan había sido publicada en $1881^{44}$, y tuvo que tener influencia entre nuestros higienistas. Resulta significativo al respecto un artículo ya mencionado de Luis Cortés, médico de la Comisión de Higiene especial de Barcelona, que era de hecho una síntesis con párrafos trascritos al pie de la letra ${ }^{45}$.

La obra de Langlebert se centra en conocer el origen de las enfermedades venéreas y los diversos síntomas y signos a los que puede dar lugar, para exponer a continuación las recomendaciones para evitarlos. Advierte sobre los peligros del charlatanismo y defiende con escaso ardor la continencia. Publicada dos años después de la identificación por Albert Neisser, en 1879, del gonococo, la enfermedad blenorrágica es definida como una inflamación de las membranas capaz de transmitirse por contagio.

Aunque la causa para el hombre es el contagio por parte de la mujer afectada de "catarro uterino" o «leucorrea», ésta no siempre ha de padecer la enfermedad para transmitirla. Es decir, cualquier mujer podía transmitir la blenorragia, pues «muchos jóvenes contraen la blenorragia con lindas jóvenes que no la tienen", aunque Langlebert subrayaba la necesidad de que se dieran como factores necesarios para la transmisión «la intervención de una excitación algo violenta, o de contactos múltiples o voluntariamente prolongados, bajo cuyo influjo la leucorrea, ordinariamente mucosa, puede hacerse purulenta y adquirir acritud suficiente para inflamar la uretra» ${ }^{46}$.

La enfermedad, podríamos decir, permanecía esperando en la mujer hasta que el hombre, mediante contactos violentos, múltiples y prolongados, se contagiaba de ella. Esta idea acerca de la epidemiología de la gonorrea - toda mujer en determinadas condiciones podía transmitir la gonorrea - sería la base, a nuestro entender, sobre la que posteriormente se desarrollaría la concepción epidemiológica de que las mujeres portadoras asintomáticas eran la más importante cantera de la enfermedad, mientras que la contribución del hombre a esta cantera sería mínima. Recientemente, estas concepciones sobre la historia natural y la epidemiología de la gonorrea han sido desechadas ${ }^{47}$.

Pero no solamente la «leucorrea», en la obra de Langlebert, era origen de la blenorragia, también lo podían ser la sangre menstrual, los loquios que suceden al parto y «en general todos los flujos naturales ó morbosos procedentes del útero ó de sus anexos». Entre las últimas causas detalladas por el autor, figuraban la masturbación, los irritantes locales, los cálculos en la vejiga, el mal de piedra y los excesos de las bebidas, particularmente la cerveza y el vino blanco.

44 LANGLebert, E.: Cartas a Emilio, op. cit., 170 p.

4s CORTÉs, L.: «Consideraciones generales acerca de la profilaxis de las enfermedades venéreas y sifilíticas", op. cit., pp. 326-330 y 358-360.

46 LANGLEBERT, E.: Cartas a Emilio, op. cit., p. 23.

47 HANSFIELD, H. H. y otros: "Asymptomatic gonorrhea in men», The New England Journal of Medicine, vol. 290 (1974), n 3, pp. 117-123; ROTHENBERG, R. B. y POTTERAT, J. J.: «Strategies for management of sex partners", en HolmEs, K. K. (Ed.), Sexually Transmitted Diseases, New York, McGraw-Hill, 1990, pp. 1081-1086. 
Si nos hemos detenido a exponer detalladamente las causas de la blenorragia en un texto de vocación ilustradora de finales del siglo XIX, ha sido para valorar la persistencia de estas causas en forma de recomendaciones a los enfermos de gonorrea a lo largo del siglo XX, años después de identificarse el gonococo y ya firmemente aceptada la teoría del germen.

Desarrollado el capítulo dedicado al origen del contagio, Langlebert pasa a describir las formas de preservarse del mismo. De ellas, la que primero recibe su atención es el condón, del que opina que «mejor sirve para encubrir el peligro que para preservarnos de él» y al que no duda en rechazar:

«Condenamos resueltamente el uso de este preservativo, más propio para provocar la repugnancia que para inspirar el deseo de una función, en la que suprime a la vez el objeto y el atractivo principal» 48 .

Sin olvidar la moderación de los deseos, especialmente después de los excesos alcohólicos, el autor considera que la utilización abundante del agua para mantener limpios los órganos genitales y la micción después del coito constituyen los métodos de profilaxis más seguros.

Debemos resaltar en el texto de Langlebert dos aspectos. Por un lado, la existencia de una visión de la mujer en tanto que reservorio de la enfermedad blenorrágica, visión que alcanza a todas las mujeres y que le une a la tradición judeo-cristiana que ve a la mujer como generadora del pecado y de la «caída». Por otra parte, la existencia de toda una serie de preceptos que podríamos denominar de higiene sexual que conforman un modelo de actividad sexual moderada y que no debe demorarse en el placer, ideas y preceptos que persisten hasta bien entrado el siglo XX.

Entre 1909 y 1910, ven la luz las traducciones de las obras del venereólogo francés Louis Jullien $E l$ «Terrible mal». Confidencias de un médico, El otro mal: Blenorragia, flujos (confidencias de un médico) y Los Pequeños Males, todas ellas prologadas por Juan de Azúa. Destinadas a la educación médica de la juventud, las obras previenen sobre los peligros de estas enfermedades y aunque basan la prevención individual en la continencia - se aprecia ya un cambio en la consideración médica de la continencia, que aparece a ojos de Jullien como un objetivo alcanzable y deseable-, añaden la difusión de otros métodos profilácticos.

Entre ellos destacan, para la prevención de la sífilis, las fricciones con pomadas de calomelanos (protocloruro de mercurio mezclado en la proporción del 1 por 3 con lanolina), que Metchnikoff y Roux habían utilizado en 1906 en sus experimentos sobre la profilaxis de la sífilis ${ }^{49}$. Aunque Jullien advertía sobre los peligros de considerarlas como absolutamente seguras, estas prácticas eran

48 LANGlebert, E.: Cartas a Emilio, op. cit., p. 35.

49 Gregorio García-Serrano, E.: Profilaxis médico-social de la sífilis. Discurso leído en la Real Academia de Medicina de Zaragoza en la recepción pública del Dr. --, Zaragoza, Industrias Gráficas Alfredo Uriarte, 1930, p. 43. 
mejor vistas que la utilización del condón del que Jullien consideraba que "ofrece una garantía relativa, limitada solamente a los sitios protegidos y a condición de su integridad absoluta» ${ }^{50}$, y cuya garantía le parecía de todas formas «bastante repugnante por sí misma». Para la prevención de la blenorragia, Jullien recomendaba los lavados con permanganato de potasa y las inyecciones de sales orgánicas de plata: el protargol, la albargina, el argirol y el electrargol.

Otros autores españoles, como Angel Pulido, escribían ya en 1908 en el Siglo Médico sobre la necesidad de divulgar las nociones profilácticas sobre la blenorragia ${ }^{51}$. Pulido opinaba que el condón, aunque efectivo cuando era utilizado en las condiciones adecuadas, era rechazado por diversos autores por disminuir el placer sexual y por cuestiones morales al considerar que su utilización convertía el acto sexual en una forma de onanismo. Continuaba insistiendo en el valor del lavado de los genitales después del coito y la micción con interrupciones del chorro de orina para aumentar la función de arrastre del gonococo. Tanto la interrupción del coito como su prolongación aparecían como factores favorecedores del contagio y terminaba sus recomendaciones con una revisión de los métodos antisépticos post-coitum, centrados en el permanganato potásico y en las sales de plata (instilaciones en la uretra de disoluciones en glicerina de las sales de plata).

Aunque el proceso de difusión de estos métodos se centraba por parte de los médicos en la prensa especializada, los tratados de la especialidad y las obras de divulgación para los jóvenes, se asiste progresivamente a una discusión sobre métodos y técnicas para prevenir individualmente las enfermedades venéreas. Para la segunda década del siglo XX, se advierte que estas recomendaciones no sólo van dirigidas a los hombres sino igualmente a «las mujeres que tienen trato frecuente con hombres».

En 1913, García Puelles aconsejaba a éstas diferentes prácticas preventivas, recomendando a las autoridades que tales medidas, tanto para los hombres como para las mujeres, se divulgaran mediante folletos, proponiendo así una difusión pública de esos conocimientos ${ }^{52}$. Con respecto al condón, el autor opinaba que «el condón, medio mecánico de protección, que, bien colocado, es el más seguro, siempre y cuando no se rompa; pero que tiene el inconveniente de repugnar a muchos, por la acción inhibidora que en ellos ejerce durante el acto venéreo».

La utilización de profilácticos para la sífilis y la gonorrea antes y después de los coitos sospechosos encontraba en la población militarizada las condiciones ideales para ser utilizada de manera obligatoria. Aunque estas prácticas alcanzaron su auge en los años posteriores a la I ${ }^{\mathrm{a}}$ Guerra Mundial, la experiencia del

50 Jullien, Louis: $E l$ «Terrible Mal». Confidencias de un médico, Madrid, Librería de los Sucesores de Hernando, 1909, p. 320.

51 Pulido Martín, Ángel: «Profilaxis blenorrágica», El Siglo Médico (Madrid), art. reproducido en Revista Española de Dermatología y Sifiliografía, 1908, pp. 318-323.

52 GARCía PUelles: "Profilaxis de la blenorragia», Medicina Española, art. reproducido en Revista Española de Dermatología y Sifiliografía, vol. 15. (1913), nº 179, pp. 620-625. 
ejército norteamericano en la aplicación de las denominadas «cabinas profilácticas» fue valorada como altamente positiva:

«Los ejércitos americanos, en 1917 , establecieron en los campos de batalla las cabinas profilácticas dedicadas exclusivamente a la realización de medidas de profilaxis. Los soldados [...] venían obligados a acudir a las cabinas profilácticas después de todo contacto sexual, siempre antes de pasar las cuatro horas. En éstas existían enfermeros convenientemente instruidos, los que realizaban un completo lavado de los genitales, instilaciones de argirol o protargol en la uretra y la aplicación de la pomada de Metchnikoff en glande, prepucio y pene, mediante una fricción de cinco minutos y la aplicación posterior de un papel de seda para conservar aplicada la pomada durante cuatro o cinco horas, después de las cuales realizaban un nuevo lavado" 53 .

Existen referencias de que en nuestro país, al menos de manera aislada, fueron utilizadas anteriormente. Para 1913, en la Marina de guerra, había sido introducida como práctica obligatoria en algunos barcos la utilización del «Viro", un preparado que incluía una grasa compuesta de calomelano y vaselina que se aplicaba a la mucosa del glande y piel del pene antes del coito, así como una pequeña cantidad de nitrato de plata que se inyectaba en la uretra después del coito ${ }^{54}$.

En 1919, la profilaxia personal era vista, sin embargo, por Eleuterio Mañueco Villapadierna, médico del hospital de San Juan de Dios y médico mayor de la Armada, como un mal que había que aceptar en tanto que otras medidas más coercitivas no se pusieran en marcha:

«Mientras no se llegue al tratamiento forzoso de las enfermedades venéreas; mientras no haya una ley que obligue a la denuncia obligatoria de estas enfermedades téngalas quien las tenga; y mientras el conocimiento de ellas y de sus peligros en la masa social sea tan deficiente como lo es en la actualidad, no tendremos más remedio que aconsejar la profilaxis personal»\$s.

Muchos médicos consideraban que estas medidas no debían exponerse abiertamente al público, ya que «el asunto de la profilaxia personal tampoco se presta por su naturaleza a ser expuesto en conferencias públicas». Por eso, Ma-

s3 Gregorio García-Serrano, E.: Profilaxis médico-social de la sífilis, op. cit., p. 44. La aplicación del tratamiento profiláctico se realizaba dentro de las tres horas del contacto sexual y no dentro de las cuatro como describía Gregorio García-Serrano. La experiencia del ejército norteamericano en la $\mathrm{I}^{\text {a }}$ Guerra Mundial puede consultarse en BRANDT, A. M.: No Magic Bullet, op. cit., fundamentalmente en el capítulo III, " The Cleanest Army in the World': Venereal Disease and the AEF".

54 ACQUARONI, J. L.: «Profilaxis de las enfermedades venéreas en las dotaciones de los buques. Memoria reglamentaria», Revista Española de Dermatología y Sifiliografía, vol. 15 (1913), pp. 570-575.

s5 MAÑUeCo Villapadierna, Eleuterio: «Profilaxia personal de las enfermedades venéreas», El Siglo Médico (Madrid), vol. 66 (1919), pp. 1049-1052 y 1076-1080. 
ñueco Villapadierna consideraba que la difusión debía realizarse a través del médico de familia:

«Ha de ser objeto sólo de pláticas amistosas de los médicos con sus clientes cuando vean el peligro a que éstos se exponen de no tomar las debidas precauciones antes de realizar los actos de que se trata»s6.

La conveniencia de difundir de manera pública las medidas de prevención individual basadas en métodos químicos y físicos no encontraba apoyo entre los sectores médicos. Para algunos, como Mañueco Villapadierna, el espacio para la difusión de esa información era pues el espacio reservado y confidencial entre el médico y el paciente.

Como ya hemos comentado, inicialmente, era el hombre el destinatario de los conocimientos sobre prevención individual. Sin embargo, a lo largo de la segunda década del siglo XX, la mujer va apareciendo en escena como destinataria igualmente de estas medidas:

«La profilaxia contra la blenorragia no es sólo importante para el hombre. La mujer la necesita igualmente. En los tiempos que corremos, esta necesidad no se limita sólo a las prostitutas" $\$ 7$.

Al hablar de los métodos para evitar el contagio de la sífilis, Mañueco Villapadierna consideraba la protección del condón limitada porque no recubría la raiz del pene ni la zona pubiana. Afirmaba que «las medidas indicadas, casi con seguridad, evitan los contagios, siempre que sean practicadas cuidadosamente tal como las hemos recomendado», pero, como él mismo reconocía, no se había llevado adelante la difusión de estos métodos entre la población:

«Nos queda en la actualidad el camino poco explorado entre nosotros aún de la aclaración sexual y la ilustración de las gentes en el modo de preservarse individualmente de estas afecciones» 58 .

Para este año de 1919, la medida había sido ya tomada en la Armada donde estas prácticas eran obligatorias, con unos resultados valorados muy positivamente ${ }^{59}$.

A pesar de todas las consideraciones de Mañueco Villapadierna sobre la utilidad de estas prácticas y la necesidad de divulgarlas entre la población, la abs-

56 Ibid., p. 1050

57 Ibid., p. 1076

58 Ibid., p. 1078.

59 Ibid., p. 1079. La cuestión de la obligatoriedad de las prácticas profilácticas individuales en la Armada y en el Ejército se desarrolla en CASTEJÓN BOLEA, Ramón: Moral sexual y enfermedad, op. cit., pp. 209-244.

Hispania, LXIV/3, núm. 218 (2004) 923-946 
tención sexual seguía considerada como la piedra angular de la estrategia de profilaxis individual:

«Pero el medio mejor de profilaxia, del cual aún nada hemos dicho, es la abstinencia sexual. Sobre esto no sólo el moralista, sino el médico, deben de insistir sobre sus jóvenes clientes. Es necesario llevar al ánimo de las gentes que la abstinencia sexual no trae ningún peligro y que, precisamente, los peligros vienen de no practicarla» 60 .

\section{¿NUEVOS PLANTEAMIENTOS EN LOS AÑOS TREINTA?}

Para la década de los treinta, la apreciación por parte de los médicos de la eficacia de los métodos preventivos individuales contra la sífilis era muy crítica. Dos hallazgos científicos, la rapidez de propagación de los treponemas y la existencia de sífilis mudas asintomáticas, cuestionaron la validez de los métodos profilácticos químicos para la sífilis. La publicación de diferentes trabajos (Gougerot en 1923 y en 1928, Fernet en 1923, Spillmann en 1929) que demostraban el contagio a pesar de la utilización tanto de métodos locales químicos como de medicaciones generales vía parenteral o gástrica - derivados salvarsánicos como el neosalvarsán parenteral o el stovarsol y treparsol vía gástrica-, puso en la picota estos métodos ${ }^{61}$.

Además, ya se contaba entonces con el denominado tratamiento abortivo (tratamiento salvarsánico iniciado antes de que la reacción de Wasserman se hiciera positiva, persistiendo la negatividad de la prueba durante todo el tratamiento), cuyos resultados eran más firmes y que suponía en la práctica la aplicación del principio de "profilaxis por el tratamiento" que la época salvarsánica había inaugurado ${ }^{62}$. Este principio se basaba en que la mejor estrategia para disminuir el contagio de la sífilis (previniendo su transmisión) era tratar los casos de sífilis lo más efectiva y rápidamente posible, logrando así disminuir la transmisión de la enfermedad.

A un médico de la profilaxis oficial antivenérea como Eduardo de Gregorio, el condón seguía planteando, como método para la prevención de la sífilis, los problemas de que protegía exclusivamente el pene y que su utilización conllevaba en la mayoría de los casos el abandono de otras prácticas preventivas, incluido el lavado jabonoso de genitales. Esta opinión no era unánime entre los médicos. Así, Manuel Garriga consideraba que «durante las relaciones sexuales, el empleo del preservativo constituye uno de los recursos profilácticos más se-

\footnotetext{
60 MaÑueco VillaPadierna, Eleuterio: «Profilaxia personal de las enfermedades venéreas», op. cit., p. 1078.

61 Gregorio García-Serrano, E.: Profilaxis médico-social de la sifilis, op. cit., pp. 40-52.

62 Bejarano, Julio: «La profilaxis por el tratamiento», Ecos Españoles de Dermatología y Sifiliografía, vol. 5 (1929), n 459, pp. 655-676.
} 
guros", si bien reconocía que "puede a veces efectuarse el contagio en la piel de la raiz del miembro y de la cara interna de los muslos»63. A Julio Bravo, médico también de la lucha antivenérea, le parecía que el condón no ofrecía en la sífilis tanta eficacia como en la gonorrea, y José Gay Prieto, catedrático de la Universidad de Granada, pensaba en 1934 que el lavado jabonoso detenido y practicado inmediatamente después del coito igualaba en eficacia al condón y a la pomada de Mechnikoff, y les superaba en comodidad ${ }^{64}$.

En 1931, Cordero Soroa, médico de los dispensarios antivenéreos de Madrid, resumía así la validez de los métodos de profilaxis individual:

"Queda en pie el valor indiscutible de los lavados jabonosos precoces y prolongados, la utilidad de la profilaxis mecánica por el preservativo o condón y el poco o nulo valor profiláctico de las diferentes pomadas propuestas y comunmente en uso" 65 .

En cuanto a la gonorrea, para la que no se disponía de un tratamiento específico - los que se utilizaban eran penosamente largos y molestos, con el consiguiente abandono de ellos por parte de los enfermos-, los métodos de profilaxis individual debían ocupar, según declaraban los mismos venereólogos desde la segunda década del siglo XX, un lugar preferente en las estrategias de lucha contra la enfermedad. Ricardo Bertoloty, uno de los venereólogos más dedicados a esta enfermedad, escribía así en 1932:

«La profilaxis individual es la piedra angular para la prevención de la blenorragia; pero su práctica adolece de defectos capitales: unos dependen del individuo (descuido de su empleo, mala técnica, uso intempestivo, suspicacias de una parte o de otra para su empleo y, por último, ignorancia); otros dependen de las medicaciones utilizadas, pues, al lado de algunas de efectividad más o menos probada, existen otras perfectamente inútiles y algunas rigurosamente perjudiciales. La verdadera profilaxis individual requiere una enseñanza adecuada y una técnica bien definida, que generalmente es mal conocida, y algún procedimiento físico bien del dominio público es rechazado por algunos por una delicadeza mal entendida, y por otros por ser un obstáculo a la satisfacción» 66 .

63 GARRIGA, Manuel: El tratamiento de la sífilis en los períodos primario y secundario, Barcelona, Ed. Labor, 1930, p. 130.

64 GAY PRIETO, Dr. José: Las enfermedades venéreas y sus profilaxis, Madrid, Editorial Cenit (Biblioteca de vulgarización médica), 1934, p. 67.

65 CORDero SOROA, A.: «Orientación moderna en la profilaxis individual de las enfermedades venéreo sifilíticas (Conferencia pronunciada en el Hospital de San Juan de Dios, en los servicios del doctor Sáinz de Aja)», Ecos Españoles de Dermatología y Sifiliografía, vol. 7 (1931), nº 74, pp. 99-110.

66 Bertoloty, Ricardo: «¿Por qué no decrece la gonorrea como plaga social?», Actas DermoSifiliográficas, vol. 25 (1932), $\mathrm{n}^{\circ}$ 2, pp. 122-126.

Hispania, LXIV/3, núm. 218 (2004) 923-946 
En 1934, el mismo Bertoloty insistía en el papel de la profilaxis individual en la prevención de la blenorragia:

«Organizada la lucha antivenérea sobre métodos científicos, la profilaxis individual con medios de verdadera solvencia y perfectamente controlados hubiera contribuido a disminuir gradual y progresivamente las cifras de infectados a medida que la educación sexual, por un lado, y por otro el conocimiento de la verdadera profilaxis, hubieran llegado a hombres y mujeres a su debido tiempo, es decir, antes de sus primeras exposiciones» 67 .

Afirmaciones de este tipo nos obligan a reflexionar acerca de las causas que condujeron a desperdiciar una de las estrategias que eran consideradas por los médicos como eficaces y útiles para disminuir la incidencia de la enfermedad. Sería difícil valorar la eficacia real de estos métodos: podemos, sin embargo, recordar que el mayor ensayo comunitario realizado sobre su eficacia se llevó a cabo en la I ${ }^{\mathrm{a}}$ Guerra Mundial por parte del ejército norteamericano. El Departamento Médico de este ejército estimó que, cuando la profilaxis se administraba apropiadamente, la efectividad era del $99.6 \%$ contra la sífilis, gonorrea y chancroide ${ }^{68}$. Bertoloty, en sus afirmaciones, habla por una parte del desconocimiento por parte de la población de las técnicas eficaces y de su mala utilización, y por otra, del rechazo que generaba la utilización del condón por una delicadeza mal entendida o por convertirse en un obstáculo para el placer.

La primera conclusión que podemos obtener es que, en nuestro país, la estrategia de profilaxis individual como un instrumento útil para enfrentarse a las enfermedades venéreas no recibió el apoyo mayoritario de los médicos. Para mediados de los años treinta, finalizando nuestro periodo de estudio, el error empieza a ser aceptado entre los sectores médicos más implicados en la lucha antivenérea.

Además, considerar que los enfermos eran responsables de la mala utilización de los métodos preventivos y de la consideración negativa del uso del condón, era obviar la responsabilidad que los médicos, y más los médicos de la lucha antivenérea, habían tenido en esa consideración y en la no difusión adecuada y definida de las técnicas de profilaxis química. Es decir, insistían en los procesos de culpabilización de los enfermos, culpabilización que formaba parte de la visión médica de estas enfermedades:

«[...] En la adquisición de toda enfermedad venérea existe cierta culpa. De otras muchas enfermedades uno no puede prevenirse, pero de las afecciones que se transmiten por el coito, sí, sin duda alguna»69.

67 BeRtoloty, Ricardo: «Un aspecto de la lucha antivenérea: el problema de la profilaxis social de la gonorrea», Actas Dermo-Sifiliográficas, vol. 27 (1934), $\mathrm{n}^{\circ}$ 2, pp. 179-183.

68 BRANDT A. M.: No Magic Bullet, op. cit., p. 111.

69 OYARZABAL, E.: «Las enfermedades venéreas y la responsabilidad médica», Revista Española de Dermatología y Urología, vol. 19 (1917), n² 221, pp. 270-291. 
Si las palabras de Mañueco Villapadierna en 1919 auguraban una mayor difusión y apoyo médico a estos métodos, las de Bertoloty en 1934 nos demuestran que esto no fue así. Las razones, a nuestro entender, que nos situaban quince años después en el mismo punto, hay que buscarlas en las resistencias de los médicos a la difusión del conocimiento de estas medidas entre la población general.

Como vimos con los Avisos sanitarios, en algunos burdeles figuraban carteles que recomendaban este tipo de prácticas - así, en Gijón, a principios de los años veinte se fijaban en las casas matriculadas cuadros murales con instrucciones profilácticas ${ }^{70}$ - y para 1919 eran obligatorias en la Armada y en el Ejército. Pero estas dos poblaciones, los usuarios de los burdeles y la marinería, eran consideradas población de riesgo que continuaba realizando prácticas sexuales peligrosas desde el punto de vista sanitario, por lo que era conveniente aplicar en ellas medidas preventivas individuales, a pesar de que se tuvieran ciertas dudas sobre su eficacia y de que su utilización retardara el diagnóstico en los casos de ineficacia.

Sin embargo, el hecho de difundir estos conocimientos entre la población general significaba, como ya apuntamos, reconocer y sancionar las prácticas sexuales ilegítimas; es más, para algunos, incluso estos conocimientos incitaban a la realización de estas prácticas en la medida en que se difundían técnicas para evitar lo que se consideraba justo castigo por la falta cometida y, además, apoyar estas técnicas dificultaba la campaña de abstención sexual que, siguiendo las recomendaciones de la $2^{a}$ Conferencia Internacional para la profilaxis de la sífilis y demás enfermedades venéreas, se proponía como el mejor método para evitar el contagio.

Tampoco habría que olvidar que métodos físicos como el condón eran además métodos anticonceptivos. Estas razones explicarían, a nuestro entender, las reticencias de los médicos a una verdadera difusión popular y la insistencia en considerar la abstención sexual como el mejor método profiláctico. La falta de apoyo a la estrategia de prevención individual a través de métodos químicos y físicos supuso, de hecho, la imposición de las tesis morales de la lucha antivenérea frente a las posiciones más secularizadas y científicas. El sector de charlatanes e intrusos y los sectores médicos menos cualificados pudieron así hacerse con un amplio mercado de "preservativos» contra las «enfermedades secretas».

Esta falta de apoyo médico a las estrategias preventivas individuales, más allá de la abstención sexual, coincide con la posición médica en esta época en lo referente al control de natalidad, que supuso igualmente, como lo ha expuesto Raquel Álvarez, el abandono de muchas mujeres en manos de charlatanes y

70 Vila BARBERA, R.: «Cómo debe organizarse la lucha antivenérea en España (Ponencia presentada al II Congreso Español de Medicina, Sevilla, Octubre, 1924)", Actas Dermo-Sifilográficas, vol. 16 (1924), n ${ }^{\circ}$ 5, pp. 335-353.

Hispania, LXIV/3, núm. 218 (2004) 923-946 
vendedores de productos anticonceptivos ${ }^{71}$. Estas posiciones médicas se veían reforzadas por el peso de la Iglesia católica y su posición sobre el tema, reflejada en 1930 en la encíclica Casti Connubii, que dedicaba sus apartados 57-58 a la «condenación de las prácticas anticoncepcionistas».

Las resoluciones de La Unión Internacional contra el Peligro Venéreo resultan igualmente reveladoras de los problemas morales que la difusión de los métodos físicos y químicos de profilaxis individual planteaba a los médicos. La Unión Internacional contra el Peligro Venéreo - actualmente Unión Internacional contra las Enfermedades Venéreas y las Trepanomatosis- fue creada en 1923 bajo la iniciativa de la Liga de Sociedades de la Cruz Roja y de la Asociación Belga contra las Enfermedades Venéreas. Sus objetivos eran aconsejar a los gobiernos y al público en general sobre las mejores medidas para controlar las enfermedades venéreas y ofrecerles información y consejo. En su primera Asamblea General, celebrada en París, tomaron parte 19 naciones, y, en 1928, la cifra había aumentado hasta 34 miembros. La Asamblea General de 1934 se celebró en Madrid, siendo entonces José Sánchez Covisa consejero del comité Ejecutivo $^{72}$.

En 1928, la Asamblea General de esta organización aprobó en Nancy una resolución referente a las pomadas profilácticas tipo Metchnikoff. Al considerar que éstas no eran una panacea, pedía a los gobiernos y a las ligas y asociaciones de propaganda antivenérea «no preconizar en su propaganda al público estos métodos de profilaxis individual, no debiendo ser recomendados más que a ciertas colectividades y con las precauciones necesarias para no confundir a la opinión pública, y por otra parte no empujar a los muchachos jóvenes a la desvergüenza y al contagio, dándoles idea de una seguridad que no es sino relativa» ${ }^{73}$.

Sin embargo, cinco años más tarde, en la Asamblea celebrada en El Cairo en 1933, esta organización aprobaba una nueva resolución. La misma no contó con unanimidad; de hecho, fue aprobada por nueve votos contra cinco, lo cual demostraba los debates que tan espinoso tema generaba. La Unión Internacional consideraba que la profilaxis individual no constituía «un medio de protección y de seguridad absoluta», pero, que sin embargo «las experiencias practicadas en los últimos años, especialmente en las armadas y en las marinas, han dado resultados preventivos reales». Por tanto la Asamblea General declaraba:

«Que una organización apropiada de la profilaxis individual puede evitar un grandísimo número de contaminaciones.

71 Álvarez Peláez, Raquel: «La mujer española y el control de natalidad en los comienzos del siglo XX", Asclepio (Madrid), vol. 42 (1990), $\mathrm{n}^{\circ} 2$ [La sexualidad y sus límites], pp. 175-200.

72 Una sucinta historia de la organización puede consultarse en WAUGH, M. A.: «The Bulletin of the Internacional Union Against the Venereal Diseases and Treponematoses», Genitourinary Medicine, ${ }^{\circ} 66$ (1990), pp. 41-42.

73 Unión Internacional contra el Peligro Venéreo, «Resoluciones adoptadas por la Unión desde su creación», Actas Dermo-Sifiliográficas, vol. 26 (1934), n²9, pp. 920-940. 
Que es, pues, del deber de cada Estado, encontrándose en las condiciones sociales preliminares indispensables de educación y de organización, el tomar medidas permitiendo a ciertas colectividades utilizar en condiciones cómodas medios de profilaxis individual de buena calidad suministrados al precio mínimo, evitando, no obstante, la publicidad y la venta de estos medios en condiciones ofensivas para la moralidad pública» 74 .

Uno de los objetivos de la campaña contra las enfermedades venéreas fue la ilustración del pueblo con respecto a los peligros de estas enfermedades y sus consecuencias, objetivo que se consiguió rompiendo la «conspiración de silencio» que rodeaba estas enfermedades y provocando un debate público sobre ellas, colaborando así a la irrupción del mundo de la sexualidad en el público en general:

«Es a nosotros a quienes corresponde romper lo que Gauducheau llama «la conspiración del silencio», enseñando directamente al público el peligro y profilaxis de estas enfermedades» 75

Pero la difusión de conocimientos para la prevención individual estuvo, sin embargo, limitada por las consideraciones sexuales y morales de la época. El posicionamiento más apoyado en la moral, firme defensor de la regeneración moral y de la abstención sexual como estrategia preventiva individual, se impuso así sobre las posiciones más seculares que se basaban en muchos casos en hallazgos científicos. De esta forma, los médicos más intervencionistas y que habían roto con la unión entre Higiene y Moral, colaboraron a romper la «conspiración de silencio» que rodeaba las enfermedades venéreas —un acto aparentemente radical - para mantener la moral sexual dominante.

Si bien la necesidad de extender a las poblaciones la idea de la importancia y gravedad de estas enfermedades no generó puntos de vista diferentes entre los médicos, no ocurrió lo mismo con las estrategias preventivas individuales, entre las que se encontraban la abstención sexual, los métodos químicos y los físicos.

Dos posiciones pueden delimitarse, pues, frente a estas estrategias de prevención individual. Para la primera, fuertemente anclada en la moral católica, la lucha contra las enfermedades venéreas se cimentaba en la regeneración moral y en la castidad. La segunda posición, más secularizada, estaba dispuesta a aceptar la realidad de una sexualidad fuera de los estrechos márgenes de la moral católica y planteaba, por lo tanto, la difusión de la utilización de la profilaxis química y física.

74 Ibid., p. 936

75 FERNÁNDEZ de la PORTILla, J. y Bravo SANFeliú, J.: «Cómo debe organizarse en España la lucha antivenérea», op. cit., p. 334.

Hispania, LXIV/3, núm. 218 (2004) 923-946 